\title{
Risk Factors Associated with Stunting and Wasting Levels Among Under Five Children in Ethiopia
}

\author{
Hulle Hassen Aman * \\ Department of Statistics, College of Natural and Computational Science, Madda Walabu University, Bale Robe, \\ Ethiopia \\ Kemal Nure Kawo \\ Department of Statistics, College of Natural and Computational Science, Madda Walabu University, Bale Robe, \\ Ethiopia
}

\begin{abstract}
Introduction: Childhood stunting is one of the most significant impediments to human development. Stunting is a major health problem in children under-five years in many low and middle income countries around the world. Wasting is sometimes referred to as acute malnutrition because it is believed that episodes of wasting have a short duration, in contrast to stunting, which is regarded as chronic malnutrition.Method: The data for the study were taken from Ethiopian Demographic Health Survey (EDHS) of year 2011. For stunting levels parallel line assumption of proportional odds model is violated. Thus, Partial proportional odds model was preferred over proportional odds model, generalized ordered logit model and multinomial logistic regression based on Akaike's Information Criterion evidence. Proportional odds model is used to analyze wasting levels since the parallel assumption of proportional odds model is not violated. Result: This study revealed that the relative frequency distributions of the stunting and wasting status of child. $16.5 \%$ are severely stunted, $20.6 \%$ are moderately stunted and $62.9 \%$ are not stunted and also shows that $1.4 \%$ of children are severely wasted, $9 \%$ are moderately wasted and $89.6 \%$ are not wasted. The result indicates that age of child in month, region, place of residence, wealth index, mothers BMI, birth order of child, incidence of diarrhea for two weeks preceding the survey, incidence of fever for two weeks before survey, mothers and husband/partner educational levels are significantly associated with stunting levels. The result also shows that age of child, wealth index, mothers nutritional status, sex of child, incidence of diarrhea and fever for two weeks before survey, type of toilet, husbands/partner and employment status of mothers are significantly associated with wasting levels. Conclusions: PPOM fitted the data adequately in predicting severity status of stunting because of POM assumption is violated but POM is appropriate for wasting status. Children younger than 11 months had low risk of stunting and wasting status than other age groups. This could be because of breastfeeding in the early stages of child growth. Children in rural areas are more likely to be stunted than children in urban areas.
\end{abstract}

Keywords: Stunting and wasting, Proportional odds model, partial proportional odds model.

DOI: $10.7176 / \mathrm{JHMN} / 63-01$

Publication date:June $30^{\text {th }} 2019$

\section{Introduction}

Malnutrition is a major public health problem faced by children under-five years as it inhibits their cognitive and physical development as well as contributes to child morbidity and mortality (WHO, 2013). These malnutrition indicators are caused by an extremely low energy and protein intake, nutrients losses due to infection or combination of both low energy/ protein intake and high nutrient loss by the mother during pregnancy or by the child after birth (WHO, 2000).

Worldwide, over 10 million children under the age of 5 years die every year from preventable and treatable illnesses despite effective health interventions (Mussie A. et al., 2014). In developing countries, malnutrition is a major health problem (Caulfield et al., 2004). Childhood stunting is one of the most significant impediments to human development, globally affecting approximately 162 million children under the age of five years. Stunting, or being too short for one's age, is defined as a height that is more than two standard deviations below the WHO child growth standards median (WHO, 2006). Stunting is a major health problem in children under five years in many low and middle income countries around the world (UNICEF, 2015). It is defined as a deficit in height relative to a child's age (De Onis M. WHO, 2006).

An estimated $80 \%$ of world's stunted children lived in just fourteen countries (India, Nigeria, China, Pakistan, Indonesia, Bangladesh, Ethiopia, Democratic Republic of Congo, Philippines, United Republic of Tanzania, Egypt, Kenya, Uganda and Sudan). Sub-Saharan Africa and South Asia were the home to three fourths of the world's stunted children $40 \%$ and 39\%, respectively (Desalegne et al., 2016).

Wasting is caused by the same factors that contribute to stunting. Actions focused on prevention such as ensuring that pregnant and lactating mothers are adequately nourished that children receive exclusive breastfeeding during the first six months of life and provision of adequate complementary feeding in addition to breastfeeding 
for children aged six to 23 months can help address both stunting and wasting (Bloem M., 2014).

Globally, 52 million children below five years of age were moderately or severely wasted, $11 \%$ decrease from 58 million in 1990. More than 29 million children below five years of age an estimated 5\% suffered from severe wasting (M. De Onis et al., 2012). Wasting was decreased by 36\% from 1990 which was 159 million while 51 million children below five years of age were wasted and 17 million were severely wasted in 2013 .

In Africa, an estimated 13.4 million children under-five years of age or $8.5 \%$ were wasted (W/H $<-2 \mathrm{SD}$ ) in 2011. These children are at substantial increased risk of death. Increasing trends in child overweight in most world regions not just the developed world. In Africa, the estimated prevalence under-five overweight increased from $4 \%$ in 1990 to $7 \%$ in 2011.

According to CSA report in 2011 EDHS nationally 44 percent of children under age five are stunted and 21 percent of children are severely stunted. Male children are slightly more likely to be stunted than female children (46 percent and 43 percent, respectively).

Overall 10 percent of Ethiopian children are wasted and 3 percent are severely wasted. Wasting or acute malnutrition is highest in children age 9-11 months (19 percent) and lowest in children age 36-47 months (6 percent). Male children are slightly more likely to be wasted (11 percent) than female children ( 8 percent). Ten percent of children in rural areas are wasted compared with 6 percent in urban areas (EDHS, 2011).

\section{Statement of the problem}

Under-nutrition can best be described in Ethiopia as a long term year round phenomenon due to chronic inadequacies of food combined with levels of illness in under five children. The nutritional and health status of children in Ethiopia are among the worst in the world. For example, almost one in every 17 babies born in Ethiopia (59 per 1000) does not survive to celebrate its first birthday and one in every eleven children (88/1000) dies before its fifth birthday. As a result, it will be challenging to reach the child survival Millennium Development Goals (reducing child mortality by $3 / 4$ ) with the current pace of mortality reduction (WB, 2011).

The annual costs associated with child under nutrition are estimated at Ethiopian birr (ETB) 55.5 billion which is equivalent to $16.5 \%$ of GDP (UNICEF, 2015). So, a research on child stunting and wasting is important. Most of the studies from DHS data in Ethiopia does not included some important variables associated with stunting and wasting and also ignore the severity of stunting and wasting. Therefore, this study attempt to investigate this gap by addressing the following research questions:

1. Which covariates are the most determinant factors for stunting and wasting levels of under-five age children in Ethiopia?

2. Which model is appropriate to stunting and wasting levels of under-five age children in Ethiopia?

\section{Objective of the study}

The general objective of this study is to identify determinants of stunting and wasting levels among under five age children in Ethiopia.

\section{Data and Methodology}

The source of data for this study is the 2011 Ethiopia Demographic and Health Survey (EDHS) which is obtained from Central Statistical Agency (CSA). The study populations are all the under five children residents of Ethiopia using the 2011 EDHS data set. In the 2011 EDHS from 11,654 under-five children, total number of children covered in the current study on the stunting and wasting status of children is based on 9370 under-five children with complete anthropometric measurements and the study considered height-for-age and weight-for-height anthropometric index as indicator of a children's stunting and wasting status respectively.

\section{Variables in the Study \\ Dependent variable}

The outcome variable of interest is stunting and wasting of child less than five years. There are anthropometric indicators of nutritional status such as height-for-age, weight-for-age and weight-for-height. These indices were based on the growth standards published by WHO in 2006. The three indices were expressed as standard deviation units from the median for the reference group. Children whose height-for-age Z-score below minus two standard deviations $(-2 \mathrm{SD})$ and $(-3 \mathrm{SD})$ from the median of the WHO reference population are considered short for their age (stunted) and severely stunted or chronically malnourished respectively. Weight-for-height index describes current nutritional status. The indicators were categorized in to severely wasted $(<-3 \mathrm{Z}$-score), moderately wasted (-3 to -2 Z-score) and non-wasted ( $\geq-2 \mathrm{Z}$-score).

The response variable of the study is stunting and wasting level, which is categorized into three ordinal categories: severely stunted or wasted, moderately stunted or wasted and if not stunted or wasted. 


$$
\begin{array}{r}
\text { stunted }=\left\{\begin{array}{rr}
1, & \text { if not stunted }(z-\text { score } \geq-2) \\
2, & \text { if moderately stunted }(-3 \leq z-\text { score }<-2) \\
3, & \text { if severely stunted }(z-\text { score }<-3)
\end{array}\right. \\
\text { wasted }=\left\{\begin{array}{rr}
1, & \text { if not wasted }(z-\text { score } \geq-2) \\
2, & \text { if moderately wasted }(-3 \leq z-\text { score }<-2) \\
3, & \text { if severely wasted }(z-\text { score }<-3)
\end{array}\right.
\end{array}
$$

\section{Independent variables}

The explanatory variables included in this study are mother's education, employment status of the mother, education of husband/partner, household income, household size, place of residence and geographical region, age of the child, sex of the child, birth interval, birth order of the childs, diarrhea and fever in the last two weeks before survey, water supplies and toilet facilities, Incidence of acute respiratory infection (such as cough) in the last two weeks, Mother's nutritional status or Mother's BMI are important factors are included in this study.

\section{Logistic regression}

Logistic regression is the most important model for categorical response data. Early uses were in biomedical studies but the past 20 years have also seen much use in social science research and marketing (Agresti A., 2002). Logistic regression models are classified according to the type of categories of response variable as follows: binary logistic regression model, multinomial logistic regression model and ordinal logistic regression models (Hosmer and Lemeshow, 2000). The binary logistic regression model is used to model the binary response variable, whereas the multinomial logistic regression is a simple extension of the binary logistic regression model where the response variable has more than two unordered categories.

\section{Ordinal logistic regression model}

The ordinal logistic regression procedure empowers one to select the predictive model for ordered dependent variables. There are several ordinal logistic regression models such as proportional odds model (POM), two versions of the partial proportional odds model-without restrictions and with restrictions, continuous ratio model and stereotype model. The most popular model in ordinal logistic is the Proportional Odds model.

\section{Assumption of ordinal logistic regression}

Dependent variable should be measured at the ordinal level.

One or more independent variables those are continuous, ordinal or categorical (including dichotomous variables). However, ordinal independent variables must be treated as being either continuous or categorical.

There is no multicollinearity. Multicollinearity occurs when you have two or more independent variables that are highly correlated with each other.

Have proportional odds, which is a fundamental assumption of this type of ordinal regression model. The assumption of proportional odds means that each independent variable has an identical effect at each cumulative split of the ordinal dependent variable.

\section{Proportional odds model (POM)}

The proportional odds model was originally proposed by Walker and Duncan (1967) as the constrained cumulative logit model and later called proportional odds model (McCullagh, 1980; Hosmer and Lemeshow, 2000). Proportional Odds Model is defined by McCullagh(1980) for ordinal logistic regression. In proportional odds model, every single cumulative logit has its own threshold value. Coefficients of the equality are independent from dependent variable categories. Thus, coefficients of the independent variable are equal to each other in every cumulative logit model (Kleinbaum and Ananth, 1997; McCullagh ). When response categories are ordered logit can directly incorporate the ordering. Define $i^{\text {th }}$ cumulative probability that the response Y falls in category $i$ or below as:

$P(Y \leq i)=\pi_{1}+\pi_{2}+\cdots \pi_{c}, i=1, \ldots \ldots . c$

The cumulative probabilities reflect the ordering with

$P(Y \leq 1) \leq P(Y \leq 2) \leq \ldots \ldots \ldots . . . P(Y \leq i)=1$

Models for cumulative probabilities do not use the final one $P(Y \leq i)$ since it equals 1 . Let $\mathrm{Y}$ takes categorical response variable with $c$ ordered categories, cumulative probability of the first c-1 of $\mathrm{Y}$ is $P(Y \leq i)=\pi_{i}, i=$ $1, \ldots, c-1$. then, the odds of the first $c-1$ cumulative are

$\operatorname{odds}(\operatorname{pr}(Y \leq i))=\frac{\operatorname{pr}(Y \leq i)}{1-\operatorname{pr}(Y \leq i)}=\left[\frac{\pi_{i}}{1-\pi_{i}}\right], \quad i=1, \ldots, c-1$

The proportional odds model the log odds of the first c-1 cumulative probability as:

$\operatorname{logit}[p r(Y \leq i)]=\log \left[\frac{\operatorname{pr}(Y \leq i)}{1-p r(Y \leq i)}\right]=\log \left[\frac{\pi_{i}}{1-\pi_{i}}\right]$ 
And the relationship between the cumulative logits of $\mathrm{Y}$ is:

$$
\log \left[\frac{\pi_{i}}{1-\pi_{i}}\right]=\log \left[\frac{\pi_{i}}{\pi_{i+1}+\cdots \pi_{C}}\right], \quad i=1, \ldots . C-1
$$

Consider a collection of $\mathrm{P}$ explanatory variables denoted by the vector $X^{\prime}=\left(X_{1}, X_{2}, \ldots . X_{p}\right)$. The relationship between the predictor and response variables is not a linear function in logistic regression; instead, the logistic regression function is used, which is the logit transformation of $\pi$.

$\pi_{i}=\frac{\exp \left(\alpha_{i}+\beta_{1} X_{1}+\cdots+\beta_{p} X_{p}\right)}{\left(1+\exp \left(\alpha_{i}+\beta_{1} X_{1}+\cdots+\beta_{p} X_{p}\right)\right)}$

Then the logit or log-odds of having $\operatorname{pr}(Y \leq i)=\pi_{i}$ is modeled as a linear function of the explanatory variables as:

$\log \left[\frac{\operatorname{pr}(Y \leq i)}{1-p r(Y \leq i)}\right]=\log \left[\frac{\pi_{i}}{1-\pi_{i}}\right]=\alpha_{i}+\beta_{1} X_{1}+\cdots+\beta_{p} X_{p}$.

Equivalent with $\log \left[\frac{\pi_{i}}{1-\pi_{i}}\right]=\alpha_{i}+\sum_{j=1}^{p} \beta_{j} X_{j} \quad i=1, \ldots, c-1$ and $j=1, \ldots, p$

Where: $\quad \alpha_{i}=$ threshold value, $\beta_{j}$ =parameter, $X_{j}=$ sets of factors or predictors.

The model assumes a linear relationship for each logit and parallel regression lines. Above equation is called proportional odds model and it estimates simultaneously multiple equations of cumulative probability. An equation is solved for each category of the dependent variable except the last one. In this model each logit has its own $\alpha_{i}$ term called the threshold value and their values do not depend on the values of the independent variable for a particular case.

The test of parallel lines or planes has two log-likelihood functions; -2loglikelihood for the model that assumes the lines or planes are parallel and -2log-likelihood for the model that assumes the line are separated. For testing parallel lines for POM, the appropriate test statistic used is chi-square statistic. When the assumption does not hold, it means that there is no parallelity between categories (Kleinbaum and Klein, 2010). Test of parallel lines used to determine whether it is reasonable to assume that the values of the location parameters are constant across categories of the response. The intercept term in the equation may vary, but the parameters would be identical for each model. If the lines are parallel, the observed significance level for the change should be large, since the general model does not improve the fit very much.

\section{The Generalized ordered logit model}

In the case where the proportional odds assumption is violated, the proportionality constraint may be completely or partially relaxed for the set of explanatory variables. Generalized ordered logit model is an ordinal logistic regression which considers order of category of the response variable with k set of explanatory variables. This model results J-1 logits without constrained the effect of each explanatory variable is equal across the logits.

The model can be expressed as proposed by Fu (1998) and Williams (2006) as follows:

$$
\begin{gathered}
\operatorname{logit}(P(Y>j / X))=\ln \left(\frac{p(Y>j / X)}{p(Y \leq j / X}\right)=\alpha_{j}+\beta_{1 j} X_{1}+\beta_{2 j} X_{2}+\cdots+\beta_{k j} X_{k,} \\
j=1, \ldots J-1
\end{gathered}
$$

Where, $\alpha_{j}$ are the intercept or cut points and; $\beta_{1 j}, \beta_{2 j} \ldots \beta_{k j}$ are logit coefficients. This model estimates the odds of being beyond a certain category relative to being at or below that category.

Generalized ordered logit model estimates the regression parameters for each explanatory variable on J-1 logit of the probability being beyond the $\mathrm{j}^{\text {th }}$ category in every logit to have different estimated values. A positive logit coefficient indicates that an individual is more likely to be in a higher category as opposed to a lower category of the outcome variable.

\section{Partial proportional odds model (PPOM)}

Partial Proportional Odds Model can be used when parallel lines assumption holds or not. This model allows some covariables with the proportional odds assumption to be modeled, but for those variables in which this assumption is not satisfied it is increased by a coefficient $(\gamma)$, which is the effect associated with each $i^{\text {th }}$ cumulative logit, adjusted by the other covariables. The general form of the model is the same as the PO model, but now the coefficients are associated with each category of the response variable.

The model has the form:

$$
\begin{gathered}
\lambda_{i}=\ln \left\{\frac{\operatorname{pr}(Y=1 / X)+\cdots+\operatorname{pr}(Y=i / X)}{p(Y=i+1 / X)+\cdots+\operatorname{pr}(Y=k / X)}\right\}=\ln \left\{\frac{\sum_{1}^{i} \operatorname{pr}(Y=i / X)}{\sum_{i+1}^{k} \operatorname{pr}(Y=i / X)}\right\} \\
\lambda_{i}=\alpha_{i}+\left\{\left(\beta_{1}+\gamma_{i 1}\right) X_{1}+\cdots+\left(\beta_{q}+\gamma_{i q}\right) X_{q}+\left(\beta_{q+1} X_{q+1}\right)+\cdots\left(\beta_{p} X_{q}\right)\right\}, i=1, \ldots, k-1
\end{gathered}
$$

It is normally expected that there is a type of linear trend between each OR of the specific cut-off points and the response variable. If there is then a set of restrictions $\gamma_{k l}$ may be included in the model to clarify this linearity. When these restrictions are included this model is called the restricted partial proportional odds model. The $\tau_{i}$ parameters are fixed scale parameters which take the form of restrictions allocated to the parameters. In this 
case for a given covariable $X_{m}, \alpha_{m}$ does not depend on the cut-off points, but is multiplied by $\tau_{i}$ for each $\mathrm{i}^{\text {th }} \operatorname{logit}$. The model becomes (Peterson and Harrell, 1990).

$$
\begin{aligned}
& \lambda_{i}=\ln \left\{\frac{\operatorname{pr}(Y=1 / X)+\cdots+\operatorname{pr}(Y=i / X)}{p(Y=i+1 / X)+\cdots+\operatorname{pr}(Y=k / X)}\right\}=\ln \left\{\frac{\sum_{1}^{i} \operatorname{pr}(Y=i / X)}{\sum_{i+1}^{k} \operatorname{pr}(Y=i / X)}\right\} \\
& \lambda_{i}=\alpha_{i}+\left\{\tau_{i}\left(\left(\beta_{1}+\gamma_{i 1}\right) X_{1}+\cdots+\left(\beta_{q}+\gamma_{i q}\right) X_{q}+\left(\beta_{q+1} X_{q+1}\right)+\cdots\left(\beta_{p} X_{q}\right)\right)\right\}, i=1, \ldots, k-1
\end{aligned}
$$

\section{Model Selection Criteria}

In this study to select the best model AIC (Akaki information criterion) was used. The model with small value of AIC is the optimal model, that means a model that close to actual one (Agresti, 2002) and the model which have few parameters to be estimated. AIC and BIC is defined as

$$
\begin{gathered}
A I C=-2 * \ln (\text { likelihood })+2 k \\
B I C=-2 * \ln (\text { likelihood })+\ln (N) * k
\end{gathered}
$$

Where $\mathrm{k}$ is the model degrees of freedom calculated as the rank of variance-covariance matrix of the parameters and $\mathrm{N}$ is the number of observations used in.

\section{Model adequacy checking}

Model building is not the final goal in regression analysis. The model adequacy checking is the main step of regression analysis after a model fit. It can measure based on diagnosing residuals and measure of influence.

\section{Results and Discussions Descriptive statistics}

The analysis presented in the study is based on 9370 under-five children with complete height-for-age and weightfor-height anthropometric index as indicator of children's stunting and wasting status respectively. Table 1 shows that the relative frequency distributions of the stunting and wasting status of child. $16.5 \%$ are severely stunted, $20.6 \%$ are moderately stunted and $62.9 \%$ are not stunted. Table below also shows that $1.4 \%$ of children are severely wasted, $9 \%$ are moderately wasted and $89.6 \%$ are not wasted.

\section{Proportional odds model for wasting}

As shown in table below (Table 2) fitted proportional odds model, Test procedure produced an insignificant chisquare value of 14.675 with 14 degree of freedom ( $p$-value $=0.401$ ) indicating that a parallel lines assumption is appropriate for the data. Hence, the proportional odds model was appropriate to analyze the wasting levels of children. Results of proportional odds model for wasting indicates that all covariates are significantly associated with wasting status (see Table 2).

\section{Interpretation of result of proportional odds model for wasting}

Age of child in month significantly influences the wasting status of children. Children whose age is 12-23 months are $(\mathrm{OR}=\exp (0.682)) 1.978$ times severely/moderately wasted as compared to those in the age group $0-11$ months, holding all other variable constant. From this we can see that children in the age group 12-23 months were more likely severely/moderately wasted as compared to children aged group 0-11 months. This could be because of breastfeeding in the early stages of child growth, mother's ability to care for the child and also due to the care that parents give to older children that may decline especially if there are younger children in the family (UN, 1985). The odds could be as minimum as 1.603 and as maximum as 2.438 with $95 \%$ confidence.

Children from rich households are $(\mathrm{OR}=\exp (-0.213)) 0.808$ times less likely severely/moderately wasted as compared to those children from poor household, holding all other variables constant. Compared with children from rich households, the chances of having worse wasting status was found to increase with decrease of household wealth condition. The $95 \%$ confidence interval for odds ratio also suggests that odds could be as minimum as 0.670 and as maximum as 0.975 .

Mother's nutritional status significantly influences the wasting status of children. Children from normal level (BMI 18.5-24.9) and overweight (BMI $\geq 25)$ mothers were 0.549 and 0.340 times less likely severely/moderately wasted respectively as compared to thinness level $(\mathrm{BMI}<18.5)$ mothers, controlling all other variables constant. This means that children from thinness level $(\mathrm{BMI}<18.5)$ mothers were more likely to severely/moderately wasted when we compare with normal level (BMI 18.5-24.9) and overweight (BMI $\geq 25$ ) mothers. The 95\% confidence interval odds ratio also suggests that odds for children from normal mothers BMI could be as minimum as 0.477 and as maximum as 0.633 and odds for children from overweight mothers BMI could be as minimum as 0.218 and as maximum as 0.529 .

Sex of child is also significantly effect on the wasting status of children. Controlling all other variable constant, children whose sex is male are 1.194 times severely/moderately wasted as compared to female children. That means male children have greater chance of severely/moderately wasted as compared to female. The odds could be as minimum as 1.042 and as maximum as 1.369 with $95 \%$ confidence. 
Children who had incidence of diarrhea in the last two weeks are 1.480 times severely/moderately wasted as compared to children who had no diarrhea, controlling all other variable constant. This means among children under age five who had diarrhea in the two weeks preceding the survey, there has been a noticeable increase in the chance of being severely/moderately wasted than children who had no diarrhea in the two weeks preceding the survey. The $95 \%$ confidence interval also suggests that the odds of severely/moderately wasting are 1.240 times as low and 1.766 times as high as compared to those not wasted.

Children who had incidence of fever in the last two weeks are 1.429 times severely/moderately wasted as compared to children who had no fever, controlling all other variable constant. This means among children under age five who had fever in the two weeks preceding the survey, have greater chance of being severely/moderately wasted than children who had no fever in the two weeks preceding the survey. The $95 \%$ confidence interval also suggests that the odds of severely/moderately wasting are 1.210 times as low and 1.685 times as high as compared to those not wasted.

When we see type of toilet facilities, children from household who had no toilet facilities were 1.324 times more likely severely/moderately wasted as compared to children from household who had toilet facilities, while holding all other variables constant. The $95 \%$ confidence interval could be as minimum as 1.127 and as maximum as 1.557 .

Husband/partner educational levels had significant influence on the wasting status of child. Children from husband/partner who had no formal education were $(\mathrm{OR}=\exp (0.270)) 1.309$ times severely/moderately wasted as compared to children from husband/partner who had primary education. Moreover, Children from husband/partner who had no formal education were $(\mathrm{OR}=\exp (0.357)) 1.429$ times severely/moderately wasted as compared to children from husband/partner who had secondary and above educational levels. In other word, the risk of having worse wasting status was found highest for children having husband/partner with no formal education compared with higher level educated husband/partner children. The odds could be as minimum as 1.125 and as maximum as 1.526 corresponding to husband/partner who had primary education and the odds could be as minimum as 1.094 and as maximum as 1.866 corresponding to husband/partner who had secondary and above education with $95 \%$ confidence.

With respect to employment status of mothers it was observed that, children whose mothers are unemployed are 1.242 times severely/moderately wasting compared to children whose mothers are employed, controlling all other variables constant. That means children from mothers who had job are less likely to be wasted as compared to children from mothers who had no job. The odds could be as minimum as 1.061 and as maximum as 1.455 with $95 \%$ confidence.

\section{Proportional odds model for stunting}

For stunting the results of the proportional odds model are given in Table 3 Having fitted proportional odds model, a test procedure was run to see whether the fitting of a proportional odds model is appropriate for the data. Test procedure produced a significant chi-square value of 97.385 with 25 degree of freedom ( $p$-value $=0.000)$ indicating that a parallel lines assumption is no longer appropriate for the evidence that we see in our data. Hence, the proportional odds model was not appropriate to analyze the severity of stunting status of children.

\section{Partial proportional odds model (PPOM) for stunting}

The results for the partial proportional odds model with logit function are presented in Table 4 as shown below with Wald test of parallel-lines assumption. Results of PPOM show that all the covariates have significant influence on the response variable. Global Wald test for the final model indicates that the final model does not violate the proportional odds assumption with p-value (0.2598).

\section{Interpretation of results of partial proportional odds model for stunting}

It is clear that the odds ratios for the children aged 12-23 months and 24+ months compared to children age group 0-11 months were about 4.293 and 5.344 respectively when not stunted is compared with moderate and severely stunted states implying that children belonging the age group 12-23 and 24+ had 4.293 and 5.344 times greater risk of being moderately or severely stunted respectively compared with age group 0-11 months. When not stunted state and moderate stunting state are compared with severely stunting state the odds ratio was found about 3.684 and 5.344 respectively for children belonging to the age group 12-23 and 24+ month compared to children age group 0-11 months implying that children belonging to the age group 12-23 and 24+ months had 3.684 and 5.344 times greater risk of being severely stunted respectively compared with children age group 0-11 months.

From PPOM when not stunted and moderate stunting state are compared with severely stunting state the odds ratio were found about 1.399 and 1.401 respectively for children lived in Affar and Ben-gumuz region compared to children lived in Tigray region implying that children lived in Affar and Beni-gumuz had 1.399 and 1.401 times greater risk of being severely stunted respectively compared with children lived in Tigray region. Specifically, odds ratios for the children whose birth order 4-6 compared to children whose birth order 1-3 were about 1.151 
when not stunted is compared with moderate and severely stunted states implying that children belonging to the birth order 4-6 had 1.151 times greater risk of being moderately or severely stunted respectively compared with whose birth order 1-3. When not stunted state and moderate stunted state are compared with severely stunted state the odds ratio were found about 1.151 and 1.182 respectively for children whose birth order 4-6 and 7+ compared to 1-3 birth order implying that children whose birth order are 4-6 and 7+ had 1.151 and 1.182 times greater risk of being severely stunted respectively compared with children whose birth order are 1-3.

Husband/partner educational levels had significant influence on the stunting status of child. Specifically, when not stunted is compared with severely and moderately stunting status, children from husband/partner who had no formal education compared to children from higher education had 1.592 times being moderately or severely stunted. When not stunted and moderately is compared with severely stunted, children from husband/partner who had no formal education compared to children from husband/partner of primary education and secondary and higher had 1.168 and 1.592 times being severely stunted respectively. In other word, the risk of having worse stunting status was found highest for children having husband/partner with no education compared with higher level educated husband/partner children.

Mother's educational levels had significant influence on the stunting status of child. Children from mothers who had no formal education were 1.397 times severely/moderately stunted as compared to children from mothers who had secondary and above educational levels. That means the risk of having worse stunting status was found highest for children having mothers with no formal education compared with higher level educated mothers children.

Place of residence of child is also significant effect on the stunting status of children. Controlling all other variable constant, children who reside in rural area are 1.489 times severely/moderately stunted as compared to children reside in urban area. That means children who reside in rural area have greater chance of severely/moderately stunting as compared to children who reside in urban area.

Children from poorest households are 1.163 and 1.285 times severely/moderately stunted as compared to those children from medium and richest household, holding all other variables constant. Compared with children from medium and rich households, the chances of having worse stunting status was found to increase with decrease of household wealth condition. Thus, children from poorest households have greater risk of severity of stunting as we compare with medium and rich households.

Mother's nutritional status significantly influences the stunting status of children. Children from thinness level $(\mathrm{BMI}<18.5)$ mothers were 1.165 and 1.674 times severely/moderately stunted as compared to normal level (BMI 18.5-24.9) and overweight (BMI $\geq 25)$ mothers respectively, controlling all other variables constant. This means that children from thinness level $(\mathrm{BMI}<18.5)$ mothers were more likely to severely/moderately stunted when we compare with normal level (BMI 18.5-24.9) and overweight (BMI $\geq 25)$ mothers.

Children who had incidence of diarrhea in the last two weeks before survey are 1.346 times severely/moderately stunted as compared to children who had no diarrhea, controlling all other variable constant. This means among children under age five who had diarrhea in the two weeks preceding the survey, there has been a noticeable increase in the chance of being severely/moderately stunted than children who had no diarrhea in the two weeks preceding the survey.

Children who had incidence of fever in the last two weeks are 1.149 times severely/moderately stunted as compared to children who had no fever, controlling all other variable constant. This means among children under age five who had fever in the two weeks preceding the survey have greater chance of being severely/moderately stunted than children who had no fever in the two weeks preceding the survey.

\section{Model comparison and Goodness of fit of model}

The model fit statistics AIC for the four models POM, GOM, PPOM and MLR for stunting are given below. Based on AIC (Table 5), the model having the minimum AIC value was preferred. Accordingly, partial proportional odds model (AIC=16010.49) found to be the best model for the stunting status of under five children data set.

\section{Model adequacy checking}

The plots of standardized Pearson residuals, deviance residuals, DFBETA, Cook's distance, leverage value with predicted probability can then be used to see the pattern of all cases. The residuals and measure of influence plots against the predictive probabilities showed that the model is adequate.

\section{Discussion}

The results of the study indicate that age of child is one of determinant associated with stunting and wasting status of children in Ethiopia. The severity of stunting and wasting was higher in children aged greater than 12 months than the age 0-11 groups. This finding is consistent with the studies conducted by Shrimpton et al. (2001); KabuboMariara et al. (2006); Nguyen and Kam (2008); Alemu et al. (2014); which revealed a rapid fall in children's height from birth to 59 months; although stunting continues after 24 months and children in the youngest age 0- 
11 months had significantly lower risk of being stunted, underweight and wasted than children in the older age groups. This could be as a result of weaning and lower breast milk intakes, which make them prone to childhood stunting.

The risk of worse level stunting is significantly higher for children whose mothers have no education and primary education level than children whose mothers have secondary and higher level of education. This finding is consistent with other studies Nure et al. (2011); Semali et al. (2015); Blessing et al. (2017). They indicated that education improves the ability of mothers to implement simple health knowledge and facilitates their capacity to manipulate their environment including health care facilities, interact more effectively with health professionals, comply with treatment recommendations, and keep their environment clean. Furthermore, educated women have greater control over health choices for their children. This finding also suggests that severity status of stunting and wasting status was found highest for the children having father's/partner with no education when compared with higher level educated fathers' children. The finding is similar to those study by Nguyes and Kam (2008); Blessing et al. (2017). Study conducted by Nguyes and Kam (2008) also reveals that children whose mothers are unemployed are severity status of wasting compared to children whose mothers are employed. This finding is consistent with the study by Nguyes and Kam (2008).

The risk of stunting is significantly higher in child whose birth order is more than four when we compare with children whose birth order is 0-3. This study is consistent with the study Sommerfelt et al. (1994); Jeyaseelan (1997); Rayhan and Hayat (2006). This study is inconsistent with the study by Habaasa Gilbert (2010) which reveals stunting was more among children of birth order 1-4 than those of order 5 and above.

The study revealed that under-five children from poor households are at a higher risk of stunting and wasting than children from rich households. This finding is similar with studies Genebo and Girma (2002); Smith et al. (2005); Alemu et al. (2014). Place of residence were found to be significant determinants of stunting status in under five children. The analysis also showed that children whose parents reside in rural areas more likely to be stunted when compared to those children whose parents reside in urban areas. This study is similar to the study conducted by Shen et al. (1996); Fotso JC and Kuate-Defo B. (2005); Loida et al. (2017).

Mother's nutritional status significantly influences the stunting and wasting status of children. Children from thinness level $(\mathrm{BMI}<18.5)$ mothers higher severity of stunting and wasting as compared to normal level (BMI 18.5-24.9) and overweight (BMI $\geq 25)$ mothers. This finding is consistent with study conducted by Pendael Zephania Machafuko (2013); Semali et al. (2015) which reveals that mother's nutritional status had positive effect indicating that children belong to thinness level $(\mathrm{BMI}<18.5)$ mothers are associated with high probability of stunting and wasting.

Male children have greater risk of severity of stunting and wasting than female children (Salah E.O. Mahgoub et al. (2006); Mandefro et al. (2015)). The result of this finding is consistent with these studies but, the covariate genders of a child are insignificant factor for stunting status. This finding also similar with the studies conducted by Salah and Nnyepi (2006). The result of this study indicates that children who had incidence of diarrhea in the last two weeks are significant factor for stunting/severity of stunting and wasting/severity of wasting as compared to children who had no diarrhea. This study is consistent with the study Alemu et al. (2014); Blessing et al. (2017). The result of this study suggests that children who had incidence of fever in the last two

weeks are significant factor for stunting and wasting status. This study is consistent with the studies conducted by Blessing et al. (2017). Type of toilet facilities is important factors that associated with child malnutrition (Tadiwos and Degnet, 2013). The result of this finding is consistent with these studies.

\section{Conclusions}

PPOM fitted the data adequately in predicting severity status of stunting because of POM assumption is violated but POM is appropriate for wasting status. Consequently, from the results of PPOM for stunting status and based on POM for wasting status we have drawn the following conclusions. The result of PPOM showed that for stunting levels age of child, region, birth order of child, child place of residence, household wealth status, mother's nutritional status, incidence of diarrhea and fever, mother's educational level and husband/partner's educational level have statistically significant effect of stunting. The result of POM reveals for wasting levels age of child, wealth status of household, mother's nutritional status, sex of child, incidence of diarrhea, incidence of fever, type of toilet, husband/partner's educational level and employment status have statistically significant effect. Children younger than 11 months had low risk of stunting and wasting status than other age groups. This could be because of breastfeeding in the early stages of child growth.

\section{References}

Agresti A. (2002). Categorical data analysis. John Wiley \& Sons, New York, 2nd edition.

Alemu Adeba, Sileshi Garoma, Habtamu Fekadu and Wondu Garoma 2014 Prevalence's of Wasting and its Associated Factors of Children among 6-59 Months Age in Guto Gida District, Oromia Regional State, Ethiopia 
Blessing J.Akombi, Kingsley E.Agho, Dafna Merom, John J.Hall and Andre M.Renzaho published January 2017 Multilevel Analysis of Factors Associated with Wasting and Underweight among Children Under-Five Years in Nigeria

Bloem M. Preventing stunting: why it matters, what it takes. In: Eggersdorfer M, Kraemer K, Ruel M, Biesalski HK, Bloem $M$ et al., editors. The road to good nutrition. Basel: Karger; 2013:1324(http://www.karger.com/ProdukteDB/Katalogteile/isbn3_318/_025/49/road_04.pdf, accessed 21 October 2014).

Caulfield, et al. Under nutrition as an underlying cause of child deaths associated with diarrhea, pneumonia, malaria and measles. American Journal of Clinical Nutrition, 2004; 80:195.

Desalegne Amare, Ayenew Negesse, Baye Tsegaye, Birtukan Assefa, and Birehanu Ayenie.Prevalence of Undernutrition and Its Associated Factors among Children below Five Years of Age in Bure Town, West Gojjam Zone, Amhara National Regional State, Northwest Ethiopia

De Onis M. WHO child growth standards: length/height-for-age, weight-for-age, weight-for-length, weight-forheight and body mass index-for-age. WHO. 2006.

Fotso JC, Kuate-Defo B. Socioeconomic inequalities in early childhood malnutrition and morbidity: modification of the household-level effects by the community SES. Health Place 2005;11: 205-25.

Fu, Vincent, K., (1998). Estimating Generalized Ordered Logit Models, STATA

Genebo Timotiows and Girma Woldemariam. (2002)."Determinants of Nutritional Status of Women and Children in Ethiopia". ORC Macro, Calverton, Maryland USA. P. 1-36. (Assessed at http://www.measuredhs. comnutrition.pdf dated May 22nd, 2007).

Habaasa Gilbert (2010); Determinants of Malnutrition among Under-Five Children in Nakaseke and Nakasongola Districts, Uganda

Hosmer, D. W. and Lemeshow, S. (2000): Applied logistic regression, John Wiley \& Sons, New York, 2 nd edition. Jeyaseelan, L. (1997). Risk factors for malnutrition in South India children. Journal of Biosocial Science, 1, 93100.

Kabubo-Mariara, J., Ndenge, G.K., and Kirii, D.M. (2006). Determinants of Children's Nutritional Status in Kenya: Evidence from Demographic and Health Surveys. Paper Presented at the Centre for the Study of African Economies Conference, University of Oxford, March 17-21, 2006.

Kleinbaum, D.G. and Ananth, C.V., (1997). Regression Models for Ordinal Responses

Loida María García Cruz, Gloria González Azpeitia, Desiderio Reyes Súarez, Alfredo Santana Rodríguez, Juan Francisco Loro Ferrer and Lluis Serra-Majem (2017). Factors Associated with Stunting among Children Aged 0 to 59 Months from the Central Region of Mozambique

M. De Onis, D. Brown, M. Blossner, and E. Borghi, Levels and Trends in Child Malnutrition. UNICEF-WHOThe World Bank Joint Child Malnutrition Estimates, UNICEF, New York, NY, USA, 2012.

McCullagh P. and Nelder J. A. (1989), Generalized linear models (2nd Ed.). London: Chapman and Hall.

Mussie Alemayehu et al (2014). Nutritional status and associated factors among under-five children, Tigray, Northern Ethiopia.

Nguyen, N.H., and Kam.S. (2008).Nutritional status and the characteristics related to malnutrition in children under-five years of age in Nghean, Vietnam. Journal of preventive medicine and public health, 41(4), 232240.

Nure, A. S., Nuruzzaman, H., Abdul, G. (2011). Mulnutrition of underfive children: Evidence from Bangladesh. Asian Journal of medical sciences 2,113-119.

Peterson, B. L., and Harrell, F. E. (1990). Partial Proportional Odds Models for Ordinal Response Variables. Applied Statistics, 39(3), 205-217.

Semali, I.A.; Tengia-Kessy, A.; Mmbaga, E.J.; Leyna, G. Prevalence and determinants of stunting in under-five children in central Tanzania: Remaining threats to achieving Millennium Development Goal 4. BMC Public Health 2015, 15, 1153. [CrossRef] [PubMed]

Shen T, Habicht JP, Chang Y. Effect of economic reforms on child growth in urban and rural areas of China. N Engl J Med. 1996;335(6):400-406

Shrimpton, R., Victoria, C.G., Onis, M.de., Lima, R.C., Blossner, M., and Clugston, G. (2001). Worldwide Timing of growth faltering: Implications for nutritional interventions. Paediatrics, 107,75-81.

Sommerfelt, A., and Stewart, K. (1994). Children's nutritional status. DHS Comparative Studies. Calverton, Maryland, USA: Macro International Inc.

Tadiwos Zewdie and Degnet Abebaw. Determinants of Child Malnutrition: Empirical Evidence from Kombolcha District of Eastern Hararghe Zone, Ethiopia. Quarterly Journal of International Agriculture 52(2013), No.4:357-372

UNICEF, Improving Child Nutrition: The Achievable Imperative for Global Progress, United Nations Children's Fund, 2013

WHO (2000) Global agenda for combating malnutrition: progress report. Geneva, World Health Organization 
World health organization. Guideline: updates on the management of severe acute malnutrition in infants and CHILDREN; World Health organization: Geneva, Switzerland, 2013).

Table 1: stunting and wasting status of children

\begin{tabular}{|l|l|l|}
\hline Stunting status & Frequency & Percent \\
\hline Not stunted & 5891 & 62.9 \\
\hline Moderately stunted & 1930 & 20.6 \\
\hline Severely stunted & 1549 & 16.5 \\
\hline Total & 9370 & 100 \\
\hline Wasting status & 8398 & 89.6 \\
\hline Not wasted & 840 & 9.0 \\
\hline Moderately wasted & 132 & 1.4 \\
\hline Severely wasted & 9370 & 100 \\
\hline Total & & \\
\hline
\end{tabular}

Table 2: Result proportional odds model for wasting

\begin{tabular}{|c|c|c|c|c|c|c|c|}
\hline \multirow{2}{*}{\multicolumn{2}{|c|}{ Covariate }} & \multirow{3}{*}{$\begin{array}{l}\text { Coef. } \\
0.682 \\
\end{array}$} & \multirow{3}{*}{$\begin{array}{l}\begin{array}{l}\text { Standard } \\
\text { error }\end{array} \\
0.107 \\
\end{array}$} & \multirow{3}{*}{$\begin{array}{l}\mathrm{Z} \\
6.38 \\
\end{array}$} & \multirow{3}{*}{$\begin{array}{l}\mathrm{P}>|\mathrm{z}| \\
0.000\end{array}$} & \multicolumn{2}{|c|}{$\begin{array}{l}95 \% \text { Confidence } \\
\text { Interval }\end{array}$} \\
\hline & & & & & & \multirow{2}{*}{$\begin{array}{l}\text { Lower } \\
0.472\end{array}$} & \multirow{2}{*}{$\begin{array}{l}\text { Upper } \\
0.891\end{array}$} \\
\hline \multirow{2}{*}{$\begin{array}{l}\text { Age of child in month } \\
(0-11 \text { as reference })\end{array}$} & $12-23$ & & & & & & \\
\hline & $24+$ & $-\overline{0} 110$ & 0.100 & $-\overline{1}$ & 0.271 & -0.307 & 0.086 \\
\hline \multirow{2}{*}{$\begin{array}{l}\text { Wealth index (Poor as a } \\
\text { reference) }\end{array}$} & Medium & 0.040 & 0.099 & 0.41 & 0.685 & -0.153 & 0.233 \\
\hline & Rich & $\begin{array}{l}- \\
0.213 \\
\end{array}$ & 0.096 & $\overline{-}-23$ & 0.026 & -0.401 & -0.025 \\
\hline \multirow[t]{2}{*}{$\begin{array}{l}\text { Mothers BMI (Thinness as } \\
\text { reference) }\end{array}$} & Normal & $\begin{array}{l}- \\
0.599\end{array}$ & 0.072 & $-\overline{8}$ & 0.000 & -0.741 & -0.458 \\
\hline & Overweight & $-\overline{1}-080$ & 0.225 & $-\overline{4}+78$ & 0.000 & -1.522 & -0.637 \\
\hline $\begin{array}{l}\text { Sex of child (Female as } \\
\text { reference) }\end{array}$ & Male & 0.178 & 0.069 & 2.55 & 0.011 & 0.041 & 0.314 \\
\hline $\begin{array}{l}\text { Incidence of diarrhea (No as } \\
\text { reference) }\end{array}$ & Yes & 0.392 & 0.090 & 4.34 & 0.000 & 0.215 & 0.569 \\
\hline \multirow[t]{2}{*}{$\begin{array}{l}\text { Type of toilet (No facilities as } \\
\text { reference) }\end{array}$} & Have facilities & $-\overline{0}-281$ & 0.082 & - & 0.001 & -0.443 & -0.120 \\
\hline & Other & $\overline{0}-413$ & 0.298 & $-\overline{1.39}$ & 0.166 & -0.996 & 0.171 \\
\hline $\begin{array}{l}\text { Incidence of fever (No as } \\
\text { reference) }\end{array}$ & Yes & 0.357 & 0.084 & 4.22 & 0.000 & 0.191 & 0.522 \\
\hline \multirow[t]{2}{*}{$\begin{array}{l}\text { Husband/partner education } \\
\text { (No education as reference) }\end{array}$} & $\begin{array}{l}\text { Primary } \\
\text { education }\end{array}$ & $-\overline{0}(270$ & 0.078 & $-\overline{3}(48$ & 0.001 & -0.423 & -0.118 \\
\hline & $\begin{array}{l}\text { Secondary and } \\
\text { above }\end{array}$ & $-\overline{0}(-357$ & 0.136 & $\overline{2}-62$ & 0.009 & -0.624 & -0.090 \\
\hline $\begin{array}{l}\text { Employment status of mother } \\
\text { (unemployed as reference) }\end{array}$ & Employed & - & 0.080 & $-\overline{2.70}$ & 0.007 & -0.375 & -0.059 \\
\hline /cut1 & - & 1.739 & 0.141 & - & - & 1.512 & 1.966 \\
\hline /cut2 & - & 3.880 & 0.116 & - & - & 3.603 & 4.156 \\
\hline
\end{tabular}

Goodness-of-fit test of overall model (Likelihood Ratio): Chi-square $=368.90, \mathrm{df}=14, \mathrm{p}$-value $=0.0000$, Pseudo $\underline{\mathrm{R}^{2}=0.0526}$ 
Table 3: Result of POM for stunting as three ordered response categories

\begin{tabular}{|c|c|c|c|c|c|c|c|}
\hline \multirow{2}{*}{\multicolumn{2}{|c|}{ Covariate }} & \multirow{3}{*}{$\begin{array}{l}\text { Coef. } \\
1.431\end{array}$} & \multirow{3}{*}{$\begin{array}{l}\text { Standard } \\
\text { Error } \\
0.090\end{array}$} & \multirow{3}{*}{$\begin{array}{l}\mathrm{Z} \\
15.99\end{array}$} & \multirow{3}{*}{$\begin{array}{l}\mathrm{P}>|\mathrm{z}| \\
0.000\end{array}$} & \multicolumn{2}{|c|}{$\begin{array}{l}95 \% \text { Confidence } \\
\text { Interval }\end{array}$} \\
\hline & & & & & & \multirow{2}{*}{$\begin{array}{ll}\text { Lower } \\
1.256\end{array}$} & \multirow{2}{*}{$\begin{array}{l}\text { Upper } \\
1.607\end{array}$} \\
\hline Age of child in month & $12-23$ & & & & & & \\
\hline (0-11 as reference) & $24+$ & 1.690 & 0.081 & 20.80 & 0.000 & 1.531 & 1.849 \\
\hline \multirow{10}{*}{$\begin{array}{l}\text { Region } \\
\text { (Tigray as reference) }\end{array}$} & Affar & 0.045 & 0.093 & 0.48 & 0.630 & -0.137 & 0.226 \\
\hline & Amhara & -0.088 & 0.087 & -1.01 & 0.314 & -0.258 & 0.083 \\
\hline & Oromia & -0.305 & 0.082 & -3.72 & 0.000 & -0.465 & -0.144 \\
\hline & Somali & -0.708 & 0.107 & -6.65 & 0.000 & -0.917 & -0.500 \\
\hline & Ben-gumuz & 0.031 & 0.093 & 0.33 & 0.742 & -0.152 & 0.214 \\
\hline & SNNP & -0.140 & 0.084 & -1.66 & 0.096 & -0.304 & 0.025 \\
\hline & Gambella & -0.912 & 0.113 & -8.10 & 0.000 & -1.133 & -0.692 \\
\hline & Harari & -0.652 & 0.125 & -5.22 & 0.000 & -0.897 & -0.407 \\
\hline & Addis Ababa & -0.586 & 0.187 & -3.13 & 0.002 & -0.953 & -0.219 \\
\hline & Dire Dawa & -0.145 & 0.110 & -1.32 & 0.188 & -0.360 & 0.071 \\
\hline $\begin{array}{l}\text { Place of residence (urban as } \\
\text { reference) }\end{array}$ & Rural & 0.401 & 0.090 & 4.48 & 0.000 & 0.225 & 0.576 \\
\hline \multirow[t]{2}{*}{ Wealth index (poor as reference) } & Medium & -0.152 & 0.062 & -2.47 & 0.014 & -0.272 & -0.031 \\
\hline & Rich & -0.249 & 0.060 & -4.17 & 0.000 & -0.366 & -0.132 \\
\hline \multirow{2}{*}{$\begin{array}{l}\text { Mothers BMI (thinness as } \\
\text { reference) }\end{array}$} & Normal & -0.152 & 0.050 & -3.04 & 0.002 & -0.249 & -0.054 \\
\hline & Overweight & -0.514 & 0.122 & -4.20 & 0.000 & -0.754 & -0.275 \\
\hline \multirow{2}{*}{$\begin{array}{l}\text { Birth order of child ( } 1-3 \text { as } \\
\text { reference) }\end{array}$} & $4-6$ & 0.141 & 0.050 & 2.83 & 0.005 & 0.043 & 0.239 \\
\hline & $7+$ & 0.068 & 0.062 & 1.11 & 0.267 & -0.052 & 0.189 \\
\hline $\begin{array}{l}\text { Incidence of diarrhea (No as } \\
\text { reference) }\end{array}$ & Yes & 0.296 & 0.064 & 4.60 & 0.000 & 0.170 & 0.422 \\
\hline $\begin{array}{l}\text { Incidence of fever (No as } \\
\text { reference) }\end{array}$ & Yes & 0.143 & 0.058 & 2.46 & 0.014 & 0.029 & 0.258 \\
\hline \multirow[t]{2}{*}{$\begin{array}{l}\text { Mothers education } \\
\text { education as reference) }\end{array}$} & $\begin{array}{l}\text { Primary } \\
\text { education }\end{array}$ & -0.043 & 0.057 & -0.75 & 0.453 & -0.154 & 0.069 \\
\hline & $\begin{array}{l}\text { Secondary } \\
\text { and above }\end{array}$ & -0.323 & 0.157 & -2.06 & 0.040 & -0.632 & -0.015 \\
\hline \multirow[t]{2}{*}{$\begin{array}{l}\text { Husband/partner education (No } \\
\text { education as reference) }\end{array}$} & $\begin{array}{l}\text { Primary } \\
\text { education }\end{array}$ & -0.066 & 0.050 & -1.31 & 0.191 & -0.164 & 0.033 \\
\hline & $\begin{array}{l}\text { Secondary } \\
\text { and above }\end{array}$ & -0.473 & 0.103 & -4.57 & 0.000 & -0.675 & -0.270 \\
\hline \multicolumn{2}{|l|}{ /cut1 } & 1.861 & 0.143 & & & 1.584 & 2.138 \\
\hline \multicolumn{2}{|l|}{ /cut2 } & 3.048 & 0.141 & & & 2.767 & 3.329 \\
\hline
\end{tabular}

Goodness-of-fit test of overall model (Likelihood Ratio): Chi-square $=1126.04, \mathrm{df}=25, \mathrm{p}$-value $=0.0000$, Pseudo $\underline{\mathrm{R} 2=0.0657}$ 
Table 4: Result of partial proportional odds models

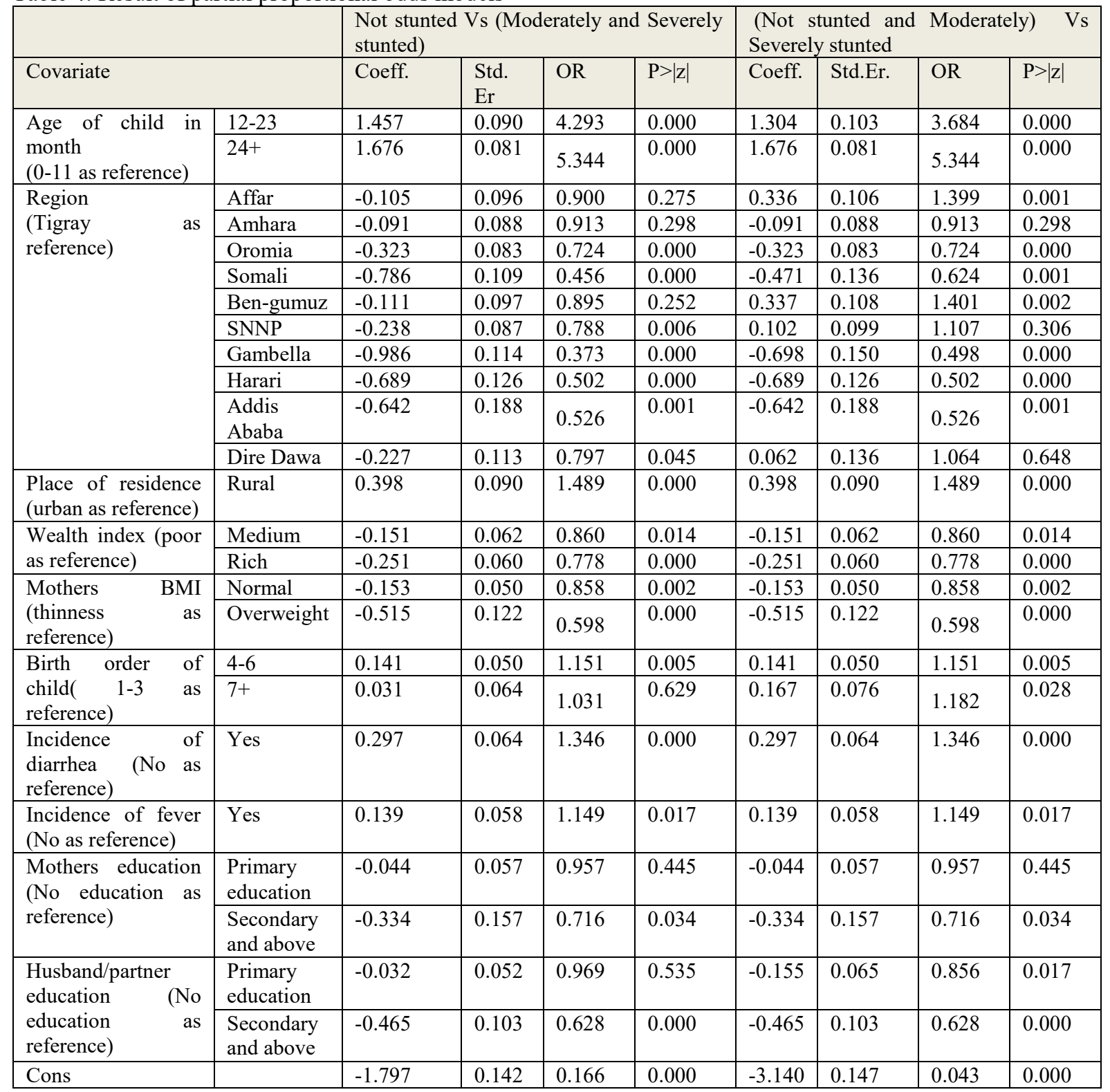

Wald test for the proportional odds assumption: Chi-square $=19.17, \mathrm{df}=16, \mathrm{p}$-value $=0.2598$

Goodness-of-fit test of overall model (Likelihood Ratio): Chi-square $=1204.26, \mathrm{df}=34, \mathrm{p}$-value $=0.0000$, Pseudo $\underline{\mathrm{R} 2=0.0702}$

Table 5:AIC for POM, GOM, PPOM and MLR

\begin{tabular}{|l|l|}
\hline Model & AIC \\
\hline POM & 16070.71 \\
\hline GOM & 16023.33 \\
\hline PPOM & 16010.49 \\
\hline MLR & 16017.82 \\
\hline
\end{tabular}

